\title{
Energy Resources Consumption Minimization in Housing Construction
}

\author{
Alexey Balastov ${ }^{1, *}$, Nikolay Kachalov ${ }^{1}$, Elena Senkiv ${ }^{1}$ and Olga Kachalova ${ }^{2}$ \\ ${ }^{1}$ National Research Tomsk Polytechnic University, 634050 Tomsk, Russia \\ ${ }^{2}$ The Russian Presidential Academy of National Economy and Public Administration, 634050 Tomsk, \\ Russia
}

\begin{abstract}
The article deals with the energy savings analysis during operation of buildings, provides the heat balance of residential premises, considers options for energy-efficient solutions for hot water supply systems in buildings. As technical facilities that allow the use of secondary heat sources and solar energy, there are also considered the systems with heat recovery of "gray" wastewater, heat pumps, solar collectors and photoelectric converters.
\end{abstract}

\section{Introduction}

Studies conducted in Western Europe show that there is a decrease in economic costs for heating and hot water supply up to $35 \%$ of total energy consumption.

In Siberia, the result of heated facilities energy saving can be the creation of energysaving life support systems for both residential buildings and thermal buildings modernization. It is necessary to find a solution in the construction of such residential premises, where the renewable energy sources are also widely used. In this direction scientists from Russia, Germany, Austria and other countries successfully work.

The idea of saving energy during the buildings operation is popular and is being realized in the whole world [1-11]. There have already been built the first experimental buildings with zero energy consumption (Null-Energie) $[1,3]$ and with their positive balance (PlusEnergie) $[4,8]$.However, the economically feasible construction of such buildings requires additional research.

\section{Energy-efficient buildings}

At the end of the last century, in the Western world, the first steps were taken in order to save heat in the operation of premises and residential buildings, which we today call energy efficient. There should be considered a multifactor aspect while the construction of energyefficient buildings, the choice of a technical solution, especially using alternate solar, wind, and geothermal energy sources. In the design and construction of energy-efficient buildings with extremely low heat losses in Western Europe, they turn to a systematic approach, but

\footnotetext{
*Corresponding author: lexiusb@gmail.com
} 
the climatic and social characteristics and economic conditions of the construction regions are not always taken into account.

The level of heat losses is reduced, the characteristics of an energy efficient building are improved as new engineering equipment is connected, the cost-saving ratio with the obtained energy savings remains optimal during the operation of an energy efficient building. For existing technical and economic operating conditions, this can be called an open energy system with an optimum level of heat consumption, and by connecting new energy efficient modules with the possibility of further lowering this level [12].

\section{Buildings heat balance}

As a rule, there aren't shared the irrevocable and irreversible heat losses when considering the thermal losses of buildings. It should be borne in mind that some losses in the building are subject to certain regulations, and this, in turn, allows a new approach to the possible optimization of the resistance to heat transfer of the buildings enclosing structures. The heat loss with exhaust air from buildings is returnable. $100 \%$ return heat of exhaust air ensures high air tightness of premises and the highly efficient heat exchangers application. Through the building enclosures, the transmission loss of heat remains irrecoverable.

\section{Characteristics of the heat consumption minimum level}

As for the heat load redistribution between individual apartments and the amount of the building heat losses there are affected the following impacts:

a) climatic conditions, with regard to which there is formed the heat balance during the building operation process,

b) socio-urban conditions that affect the heat losses level,

c) housing stock structures and the power of thermal emissions in the building, as a result of the construction process that determine their compactness

d) tenants accidental exposure on the parameters of the apartments microclimate.

Building enclosure structures resistance to the heat transfer can be taken via highefficiency heat exchangers in order to utilize heat loss during the ventilation and based on the equality of the total energy value of internal heat sources with the average transmission heat loss in the building during the heating season.

The building enclosures heat transfer resistance comparative analysis of the regulatory requirements values in countries of Western Europe and in Siberia suggests that the resistance to heat transfer is somewhat greater for virtually all types of enclosing structures, except for the floor slabs above the basements.

The window structures heat transfer resistance value exceeds the same value for all countries except for Siberia and Finland. The heat transfer resistance should, in our opinion, be close to the optimal value for specific economic and climatic conditions.

The heat transfer resistance of the enclosing structures for the medium and high storeys buildings is below the optimum value, so it can be adopted as a normative one. The heat economy for medium and high storeys buildings ventilation and heating should be transferred to the heat utilization area of the ventilation emissions from the heated buildings and engineering equipment improvement. Ventilation systems automation at the same time, gives the opportunity to save energy by controlling system modes and thermodynamic parameters depending on the time of day and climatic characteristics

\section{Options for energy-efficient solutions of buildings hot water supply systems}


In modern buildings in Western Siberia, the heat cost for heating buildings is lower than the cost for domestic hot water.

There is needed more energy saving in the development of energy efficient hot water systems, including individual hot water meters lcounters installation.

In addition to the secondary heat sources and solar energy use, we will consider other options for energy-efficient solutions for hot water systems:

- "gray" wastewater heat utilizing systems;

- heat pumps

- solar collector

- photoelectric converters.

Toilets and kitchens individual drainage system should be allocated for the "gray" wastewater heat utilization, that undoubtedly makes it possible to reduce the current and capital costs for the wastewater treatment system [13].The waste heat recovery system allows to provide the first stage of tap water heating.

Designed after the waste water heat recovery to utilize the low-potential gray" wastewater heat the Heat Pumps are the second-stage utilizer. The heat pump provides the possibility of environmentally friendly and economical heating, using the warmth of the environment.

Mounted mainly in the south on the buildings roof solar collector is designed to convert the heat energy of solar radiation into heat, that is further used in the second stage of tap water heating.

Photoelectric converters are designed to convert solar energy into electrical energy, while ensuring the compression heat pump operation.

The provided analysis of the above considered options has shown the absolute economic efficiency of the waste water heat energy utilization application. The year-round use points to the advantage of this system to a solar collectorThe solar collector and waste heat exchanger combination increases not only the energy savings, but also the capital costs. However, only the third option provides full thermal energy costs coverage for hot water supply.

\section{Conclusion}

1. The energy-efficient technologies used in the buildings design and construction, as well as the technical means and methods used to reduce the energy operating costs in the residential buildings operation in Western Europe and Siberia, have common regularities despite the different climatic conditions.

2. Heat exchangers application helps to utilize heat losses during air exchange. Based on the equality for the heating season of the transmission heat losses mean value to the total value of the solar energy and the energy of the heat internal sources in the building, it is possible to take building enclosing structures heat transfer resistance.

3. Practically for all types of building enclosures, the heat transfer resistance value in Siberia is greater than or equal to the performance statutory indicator.The only exceptions are the floor slabs above the basements

4. For specific economic and climatic conditions, the heat transfer resistance should be close to the optimum value.

5. The economy of ventilation heat and high and medium-level storeys buildings heating should be transferred to the field of buildings engineering technical equipment improvement.

\section{References}


1. A. Costa, Internationale Passivhaustagung, 485 (2010)

2. Z. Szalay, Internationale Passivhaustagung, 491 (2010)

3. A.E. Elokhov, Technologies for Designing and Building Energy-Efficient Buildings Passive House, 11-12,115 (2012) [in Russian]

4. H. Ronacher, Internationale Passivhaustagung, 525 (2010)

5. P. Regner, Internationale Passivhaustagung, 203 (2010)

6. O.I. Panitkov, Technologies for the design and construction of energy efficient buildings Passive House, 6 (7), 23 (2011) [In Russian]

7. V.A. Leonova, Technologies for the Design and Construction of Energy-Efficient Buildings Passive House, 6 (7), 26 (2011) [In Russian]

8. A.E. Elokhov, Technologies of designing and construction of energy efficient buildings Passive House, 3 (4), 57 (2013) [In Russian]

9. S. Glushkov, N. Kachalov, E. Senkiv, V. Glushkova, MATEC Web Conf. 92 (2017)

10. O. Seppanen, Energy saving, 7, 42 (2010) [In Russian]

11. B. Anderon, Solar Energy (Building design fundamentals) (Stroiizdat, Moscow, 1982) [In Russian]

12. V.G. Gagarin, ABOK, 1, 10 (2009) [In Russian]

13. I.M. Kalinin, Ecological systems, 6, 12 (2003) [In Russian] 